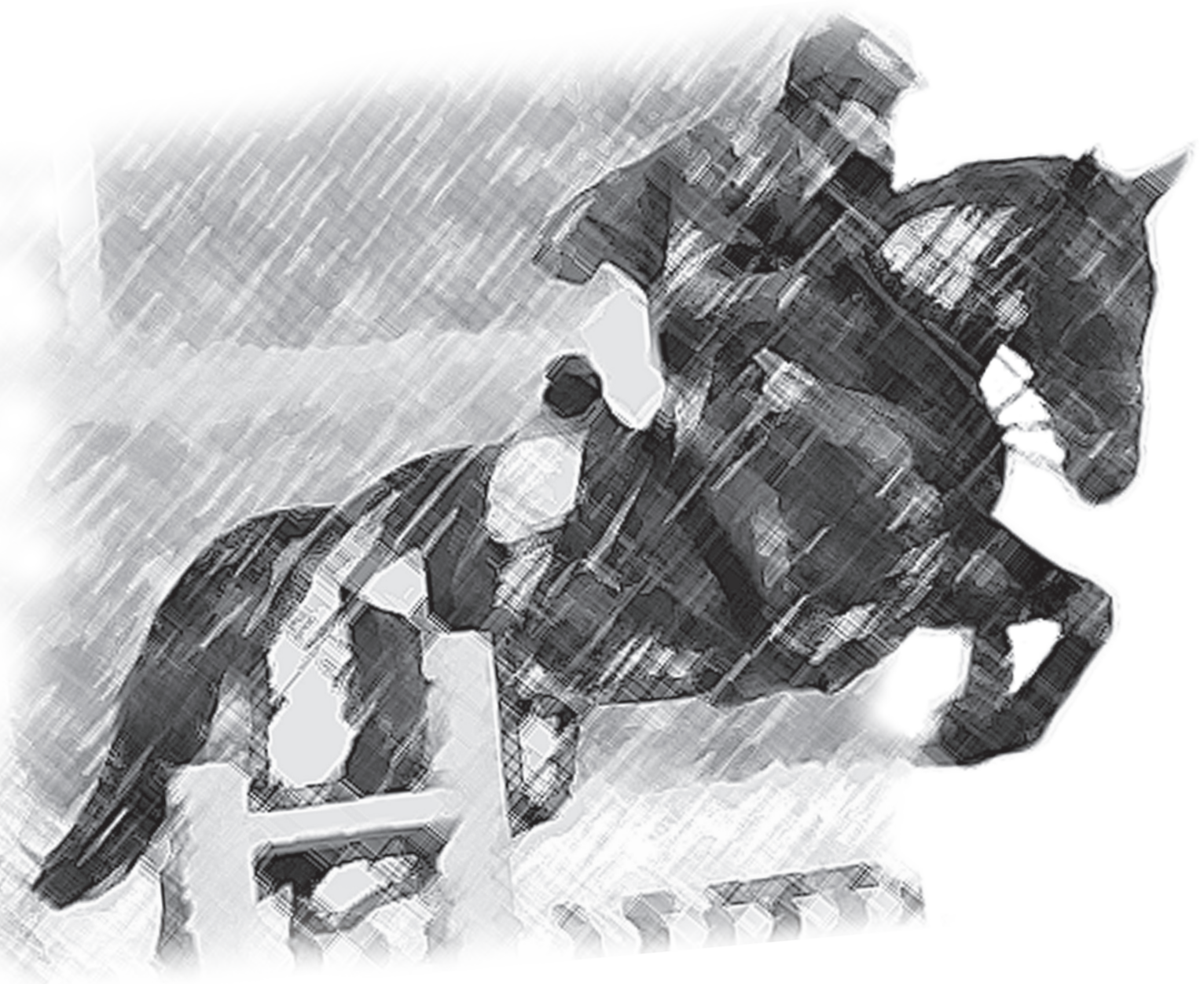

\title{
Rio de Janeiro 2016:
}

\section{a cidlade em movimento}

Gilmar Mascarenhas 


\section{resumo}

Para sediar os Jogos Olímpicos de 2016, a cidade do Rio de Janeiro tem vivido um período de transformações materiais e simbólicas sem paralelo em seus 450 anos de história. Neste artigo, tentamos oferecer um panorama essencial do conjunto das transformações urbanas e argumentar sobre como tais intervenções correspondem a um modo de gestão urbana, que David Harvey (1996) identificou e sugeriu chamar de "empreendedorismo urbano".

Palavras-chave: Jogos Olímpicos de 2016; Rio de Janeiro; planejamento urbano.

\section{abstract}

In order to host the 2016 Olympic Games, Rio de Janeiro city has experienced an unprecedented period of symbolic and material transformations in its 450-year-long history. In this article we seek to offer an essential panorama of the urban changes, and to discuss how such interventions correspond to a specific type of urban governance, which David Harvey (1996) has identified and coined as urban entrepreneurialism.

Keywords: 2016 Olympic Games; Rio de Janeiro city; urban planning. 


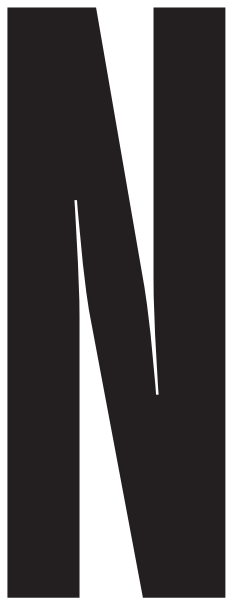

os últimos seis anos, a cidade do Rio de Janeiro viveu um período de transformações materiais e simbólicas aparentemente sem paralelo em seus 450 anos de história. A intensa mobilização de recursos financeiros provenientes das três esferas de governo (federal, estadual e municipal) vem promovendo profundos e acelerados processos de reorganização do espaço urbano.

Recursos que chegaram em volumes que não se viam desde os anos 1960 e 1970, quando da tácita "compensação" federal pela perda da "capitalidade" da Cidade Maravilhosa. Naquela ocasião, a cidade concentrou a quase totalidade dos investimentos em projetos de cunho eminentemente rodoviarista (os grandes túneis Rebouças e Santa Bárbara, viadutos diversos, o Elevado da Perimetral, a Ponte Rio-Niterói, o Elevado Paulo de Frontin, etc., com abandono definitivo dos velhos bondes) e no extenso programa de remoção de favelas. Foram adiadas obras fundamentais como o Metrô, somente inaugurado em 1979 e com traçado muito modesto. No momento em que revive, em certa medida, a aura de capital (centro das atenções), a cidade reincide no anacrônico modelo rodoviarista, embora sem deixar de investir em modalidades sobre trilhos, com destaque para o VLT, e em ciclovias. E retoma, como outrora, o “fantasma das remoções", nesta nova rodada de modernização capitalista da cidade.
Arriscamos afirmar que, na contramão das tendências em curso, isto é, do evidente processo de transição vivido atualmente no universo do movimento olímpico internacional, o Rio de Janeiro caminha para desenhar a última edição faustosa e megalômana da história recente dos Jogos Olímpicos de Verão. As edições futuras tendem a custar bem menos, pois serão favorecidas pela nova política do sistema olímpico, que visa a reduzir custos e impactos dos jogos e assim atenuar o evidente desgaste da imagem olímpica ${ }^{1}$.

Explicamos nossa hipótese: temos presenciado uma série inédita de desistências de candidaturas olímpicas nos últimos anos (Oslo, Munique, Saint Moritz-Davos, Roma, Cracóvia, Graubündem, Lviv, Estocolmo e, mais recentemente, Boston,

\footnotetext{
1 Paris anuncia para 2024 um projeto olímpico com orçamento equivalente à metade da edição carioca de 2016. Em julho de 2015, mediante contestação social intensa, o governo japonês decidiu pela revisão radical do projeto do estádio olímpico para os Jogos de 2020, reduzindo bastante seus custos. Imediatamente, o presidente do Comitê Olímpico do Japão, Yoshiro Mori, formalizou pedido de desculpas ao COI. Este, por sua vez, e já demonstrando o novo "espírito" de tentar amenizar a desgastada imagem do urbanismo olímpico, aceitou o pedido, afirmando: "We highly respect this gesture", nas palavras de Thomas Bach (Reuters, 1 august, 2015).
}

GILMAR MASCARENHAS é professor associado do Instituto de Geografia da UERJ, líder do grupo de pesquisa Megaeventos Esportivos e Cidades, membro permanente do Programa de Pós-Graduação em Geografia (PPGEO) da UERJ e pesquisador do CNPq. 
Hamburgo, Baku e Toronto, para citar apenas algumas), impulsionadas, quase sempre, embora em níveis distintos, pela contestação da sociedade civil em relação aos gastos exorbitantes, somados aos impactos e legados questionáveis; diante dos fatos, o Comitê Olímpico Internacional percebeu a necessidade de promover alterações no modelo vigente. Nesse sentido, a $127^{\mathrm{a}}$ sessão do COI, realizada em Mônaco, em dezembro de 2014, aprovou a Agenda $2020^{2}$, que, embora muito timidamente, flexibiliza algumas das exigências e claramente sinaliza para possibilidades de redução dos custos do evento. E, mais recentemente, na Assembleia Geral do COI, realizada em agosto de 2015, na Malásia, ficou decidida a supressão das etapas eliminatórias no processo de eleição das cidades-sede olímpicas, o que entendemos como expressão direta da redução drástica do volume de candidaturas.

Em suma, o movimento olímpico percebe o desgaste de um determinado modo de produzir seus megaeventos, que se consolidou nas últimas três décadas. Os Jogos Olímpicos de Londres 2012 já apresentaram uma concepção relativamente distinta do padrão hegemônico, ao menos no que diz respeito ao baixo volume de remoções de moradores e na opção pelo investimento maciço em área periférica no contexto metropolitano londrino. Esse modelo de urbanismo olímpico, que julgamos em decadência, se caracteriza pela monumentalidade exacerbada e pelo excesso de exigências que vinham tornando extremamente dispendiosa cada edição da Olimpíada, bem como pelo modesto (quando não inexistente) grau de consulta popular sobre os projetos de candidatura.

Nesse sentido, os Jogos Olímpicos do Rio de Janeiro 2016 podem sinalizar o apogeu de um modelo perdulário, autoritário, passível de produção de "elefantes brancos" (embora, a partir de 2013, os organizadores tenham redirecionado a orientação geral, passando a conceber a chamada "arquitetura nômade": instalações como a Arena do Futuro, que será desmontada para gerar escolas em outros locais) e de exageradas remoções de moradores (por vezes violentas), em claro desrespeito (e violação)

2 Disponível em: http://www.olympic.org/documents/olympic_agenda_2020/olympic_agenda_2020-20-20_recommendations-eng.pdf. Acesso em: março de 2015. aos direitos humanos. Ademais, poderá se tornar uma das edições mais contestadas e conflituosas da história olímpica. Tais elementos colocam os Jogos Olímpicos de 2016 numa posição relevante para todos aqueles dedicados ao estudo dos megaeventos esportivos e das novas tendências em curso.

O presente artigo busca oferecer um panorama essencial do conjunto das transformações urbanas, no âmbito do que denominamos "produção da cidade olímpica" no Rio de Janeiro. Tentaremos demonstrar que este processo se inicia muito antes de outubro de 2009, quando da escolha da cidade para sediar os Jogos Olímpicos de 2016, remontando ao início da década de 1990. As argumentações aqui apresentadas são desdobramento e atualização de pesquisas e publicações anteriores (Mascarenhas, 2014, 2012, 2011, 2010 e outros).

Para traçar um panorama conciso, diante do amplo espectro de intervenções no espaço urbano (Bienenstein et al., 2012), nos deteremos nas duas áreas mais afetadas pela "produção da cidade olímpica": a Barra da Tijuca (o "coração" dos Jogos Olímpicos) e a zona portuária. Muito mais que um relato do impactante processo de transformação material, pretendemos argumentar sobre como tais intervenções correspondem e traduzem um processo mais amplo de mudança no sentido da gestão urbana, no âmbito daquilo que David Harvey (1996) sugeriu chamar de "empreendedorismo urbano". Um modo específico de gerir a cidade, pautado na aliança explícita com os grandes interesses privados ou, conforme Carlos Vainer (2000), na "democracia direta do capital".

\section{ANTECEDENTES DA CIDADE OLÍMPICA}

Para entender o projeto olímpico carioca, devemos retroceder a 1992, quando foi firmado acordo de cooperação internacional (a Declaração Rio-Barcelona 1992) prevendo uma agenda de operações conjuntas, incluindo a elaboração de novas estratégias de desenvolvimento. A consultoria catalã, inspirada na conhecida retórica empreendedorista de Castells e Jordi Borja, se fez presente na elaboração da estratégia de reativar a economia urbana e promover a imagem da cidade a partir da realização de eventos globais, como as Olimpíadas.

E assim a cidade do Rio de Janeiro se candidatou aos Jogos Olímpicos de 2004. Naquele ano de 
1996, a cidade encontrava-se sob a gestão de César Maia, prefeito eleito com base no discurso da ordem moralizante, da segurança pública e da retomada do crescimento econômico, receituário que, na mesma época, Neil Smith (1996) definiu como o da "cidade revanchista", a partir da experiência de Nova York.

Em circunstâncias distintas das que geraram mais tarde o projeto de realização dos Jogos Pan-Americanos de 2007 e seu desdobramento direto, os projetos olímpicos de 2012 e 2016, a elaboração do projeto de candidatura para 2004 baseou-se na perspectiva de intervenção urbanística pautada na redistribuição espacial de recursos e de equipamentos, para tornar a cidade menos perversa em sua geografia social. Naquela ocasião, contamos evidentemente com as recomendações catalãs, que nos trouxeram a perspectiva do "equilíbrio urbano", ou seja, a preocupação com a distribuição espacial das instalações, e o princípio de priorizar o uso de terras públicas, para desonerar o evento ${ }^{3}$.

Perdeu-se, todavia, aquela disputa para Atenas, mas a cidade do Rio de Janeiro conquistou em 2002 o direito de enfim sediar um evento olímpico de menor porte: os Jogos Pan-Americanos de 2007. O que se nota é que o planejamento urbano que envolve este evento apresenta princípios bastante distintos daqueles que nortearam a candidatura anterior. Desta vez, sem qualquer canal de negociação com a sociedade civil e movida por um urbanismo mercadófilo, a gestão da cidade se orienta no sentido de atender aos diversos interesses empresariais, concentrando em área nobre (o entorno da Barra da Tijuca) a maior parte dos investimentos: a vila olímpica e boa parte das instalações esportivas.

O projeto olímpico 2016, em grande medida, reproduz esta perspectiva de cidade e de Jogos Olímpicos "espetaculares". Governo local basea-

3 Pelo projeto, a então abandonada Ilha do Fundão teria adquirido um aproveitamento intensivo de seus vastos espaços, tornando-se privilegiada concentração de equipamentos esportivo-recreativos. Nela seriam construídos a vila olímpica e grande número de instalações esportivas. Vale ressaltar que tal infraestrutura estaria ao alcance de segmentos sociais de baixa renda, que habitam o entorno imediato da ilha, medida salutar em face da crônica carência de opções de lazer para os habitantes da zona norte da cidade, que não desfrutou historicamente dos caudalosos investimentos públicos da zona sul, nem apresenta a morfologia moderna e descompactada da zona oeste, para onde se dirigem atualmente muitas das iniciativas no setor de lazer. do em instâncias decisórias fugazes, com mínima transparência, de modo que a dimensão político-institucional se manteve basicamente a mesma que produziu o Pan 2007, à exceção de um detalhe fundamental: se fortaleceu a partir da inédita coalizão dos três níveis de governo (local, estadual e nacional). Esmagada pelo poderio de tal coalizão, a dimensão cidadã foi desvalorizada, mas se ergueu pela via da mobilização popular: através do Comitê Social do Pan (atuante de 2005 a 2009) e do Comitê Popular da Copa e das Olimpíadas (de 2009 aos dias de hoje). A dimensão simbólica, por sua vez, manteve a concepção dominante já presente em 2007: o mito do grande evento capaz de salvar e alavancar a economia urbana, e o esporte como portador inequívoco de uma mensagem de saúde, regeneração, alegria, vigor e disciplina.

Com relação à dimensão físico-territorial, mantiveram-se o desprezo absoluto pela periferia metropolitana (ao contrário dos Jogos de Barcelona) e a concentração espacial das instalações no entorno da Barra da Tijuca. O projeto, todavia, sofreu alteração significativa mesmo após a confirmação da cidade como sede dos jogos: através de poderosa articulação entre o setor empresarial e órgãos governamentais, foi gerado um grande projeto de reforma da zona portuária da cidade. Como pretexto para empreender essas transformações, decidiu-se que ali seriam instaladas as vilas de mídia e de árbitros, conforme veremos a seguir.

\section{O PORTO "MARAVILHA"}

Para compreender a pesada e repentina investida do poder público e do grande capital sobre a zona portuária carioca é preciso retroceder historicamente. Na primeira década do século XX, a cidade construiu seu moderno porto, aterrando todo o entrecortado trecho litorâneo preexistente, repleto de colinas e pequenas praias, criando um retilíneo corredor de quatro quilômetros de extensão. Em 1940, a abertura da Avenida Presidente Vargas contribuiu para isolar a zona em relação ao centro da cidade, que já se verticalizava, gerando um contraste paisagístico entre este e a zona portuária, com seu casario colonial, velhas igrejas e atividade econômica pautada em pequenas unidades remanescentes do primeiro surto industrial carioca e na labuta braçal da estiva. 
Considerada zona obsoleta desde o início do processo de modernização técnica (conteinerização) e preenchida em grande parte por galpões abandonados e habitações de baixa renda, a zona portuária há muito vinha despertando a cobiça empresarial, interessada em modelos e experiências internacionais considerados bem-sucedidos em reforma/requalificação/revitalização/renovação (terminologia desprovida de conteúdo crítico) das áreas portuárias (Baltimore, Canary Wharf, em Londres, Puerto Madero, em Buenos Aires, e tantas outras) (Massey, 2007).

E, assim, o Rio de Janeiro, aproveitando a febril conjuntura "olímpica", propõe a retomada do contato da cidade com a orla, com sofisticação e monumentalidades, sob a denominação de projeto Porto Maravilha. Sem abrir efetivos canais de diálogo com a população residente ou com entidades da sociedade civil carioca, o projeto constitui um gigantesco pacote de intervenções.

Vale registrar que a zona portuária não constava originalmente na candidatura olímpica. Somente 50 dias após a cidade ter sido eleita pelo COI (o que aconteceu em 2 de outubro de 2009), foi aprovada a Lei Complementar 101, seguida imediatamente de outras iniciativas (leis 102, 103, etc.), que tratam da criação da operação urbana Porto Maravilha. Na retórica do empreendedorismo urbano, aplica-se amiúde a expressão "janelas de oportunidade" para grandes negócios. De fato, os Jogos Olímpicos propiciaram ao grande capital um contexto único para adentrar a zona portuária, contando com amplos recursos públicos, flexibilização dos marcos legais e facilidades de investimento, num megaprojeto urbanístico legitimado pelas estratégias discursivas associadas aos megaeventos esportivos.

Assim, o comitê organizador Rio 2016 decidiu imediatamente inserir a vila de mídia e a vila de árbitros na zona portuária, numa atitude que, avaliamos, buscava essencialmente reforçar e legitimar o grande projeto político capitaneado pela gestão municipal, mais do que efetivamente julgar tal medida como adequada à logística dos jogos, considerando-se a enorme distância física entre este e o local central do evento, o parque olímpico na Barra da Tijuca. A favor dessa hipótese, temos o ato de desistência desse projeto mais tarde, em 2013, transferindo as referidas vilas para local vizinho ao parque olímpico (Broudehoux \& Sánchez, 2015). Portanto, no que tange às suas relações com o projeto Rio 2016, a zona portuária abrigará apenas o "Boulevard Olímpico", espaço público "gastronômico" com telões (para exibir provas) e shows musicais. Ou seja, a condição de "cidade olímpica" (bem como certas decisões posteriormente abandonadas) contribuiu para produzir uma conjuntura especificamente favorável a grandes empreendimentos, tais como o projeto Porto Maravilha.

Nesse processo avassalador, a remoção de moradores adquire tons dramáticos, sobretudo no Morro da Providência. Para além da zona portuária, amplos espaços da cidade têm sido alvo de intervenções, com índices inéditos de desapropriações e remoções, especialmente para a construção de corredores viários, razão pela qual trataremos doravante da Barra da Tijuca.

\section{A BARRA DA TIJUCA, "CORAÇÃO" DOS JOGOS E ALMA DO NEGÓCIO}

Conforme frisamos anteriormente, foi pensado em 1996 um projeto de Olimpíada que teria na zona norte do Rio de Janeiro (área vizinha às maiores favelas da cidade, os complexos do Alemão e da Maré) seu cluster principal. E bem sabemos que a cidade apresenta diversas outras áreas passíveis de acomodar grandes projetos urbanos. Todavia, a consolidação da via neoliberal de gestão urbana propiciou maior articulação com grandes interesses privados, de modo que os projetos seguintes elegeram a Barra da Tijuca, principal eixo de expansão imobiliária de médio e de alto padrão do Rio de Janeiro, como espaço preferencial para acolher os Jogos Olímpicos.

Tal opção, além de acelerar o avanço do setor imobiliário e de toda uma concepção urbanística já superada, baseada no automóvel particular, favoreceu grandes agentes privados atuantes no local e promoveu intensa degradação ambiental, com destaque para o campo de golfe ${ }^{4}$. Para além de todos esses

\footnotetext{
4 A despeito de ampla contestação de ativistas, o campo de golfe olímpico está construído em área de proteção ambiental, a Reserva de Marapendi. O projeto envolve interesses privados no setor imobiliário, com a construção de gigantesco empreendimento favorecido por alteração das normas urbanísticas no local.
} 
impactos, outros agravantes se colocam nesse processo. Por um lado, a política de transporte intrametropolitano, considerada pelo discurso oficial como um dos principais legados dos jogos, concentrou todo o planejamento em torno da Barra da Tijuca como suposta "nova centralidade" da cidade. Três grandes vias urbanas foram criadas, todas dotadas de faixa exclusiva para "corredores" de ônibus (os chamados BRTs: bus rapid transit), o que a princípio corresponderia a demandas sociais de transporte público de maior velocidade. Todavia, além da persistência no modelo rodoviário (poluente e de baixa eficácia em termos quantitativos), todas as três vias partem da Barra da Tijuca, como se esse bairro tivesse, subitamente, se transformado no novo centro da cidade. Somente muito mais tarde, no final de 2014, após severas críticas por parte de especialistas e de movimentos sociais, o poder público reconheceu que o principal fluxo cotidiano de deslocamento de trabalhadores não havia sido contemplado, decidindo pela construção de um quarto "corredor", o da Avenida Brasil, denominado TransBrasil.

Também o sistema de transporte sobre trilhos, o Metrô do Rio de Janeiro, foi gravemente afetado pela eleição da Barra da Tijuca como "coração" dos jogos. O Metrô da cidade, reconhecidamente de alcance deveras limitado, há muito carecia de investimentos para expansão, através de novas linhas previstas muito antes da candidatura olímpica. Com o advento dos jogos, o poder público decidiu alterar o projeto anterior, de forma a expandir o sistema unicamente até a Barra da Tijuca, ignorando necessidades de tantos outros bairros (sobretudo em espaços periféricos) e aspectos técnicos fundamentais: a invenção de uma linha contínua (prolongamento da Linha 1), de longa extensão, desde o centro da cidade até a Barra da Tijuca, sem conexões que permitam desafogo, vai certamente gerar problemas crônicos de superlotação.

O movimento popular "O Metrô que o Rio Precisa" produziu uma crítica bem documentada a esse projeto que subordina todo um traçado de linhas de transporte a um único megaevento. Também o Clube de Engenharia se pronunciou diversas vezes, denunciando a inviabilidade técnica do projeto, mas o governo estadual seguiu adiante, comprometido com acordos que privilegiam determinados interesses em detrimento do bem-estar da maioria da população.
Outro impacto de alta visibilidade da escolha da Barra da Tijuca como epicentro dos Jogos Olímpicos recaiu sobre diversas comunidades e ocupações no entorno, com destaque para a antiga comunidade residente: a Vila Autódromo. Como decorrência de um claro projeto de valorização imobiliária calcada na remoção de comunidades carentes, o poder público decidiu pela extinção da comunidade Vila Autódromo, sem qualquer alegação razoável, pois sua presença não afetaria o pleno funcionamento das obras, tampouco a realização da Olimpíada. O próprio COI jamais objetou a presença da comunidade, assim como a Fifa não exigiu a retirada dos ocupantes da Aldeia Maracanã. O que não impediu o acionamento de forças militares para garantir uma concepção elitista de cidade e de megaevento.

A comunidade, todavia, demonstrou grande capacidade de mobilização e resistência à remoção, o que sensibilizou uma rede de intelectuais comprometidos com a causa, resultando na elaboração conjunta do Plano Popular da Vila Autódromo, em 2013. Não obstante toda a mobilização e seu alcance internacional, o poder público persistiu em sua investida, promovendo a remoção física de quase toda a população, restando, quando terminávamos o presente artigo, uma minoria de resistentes moradores (menos de um quinto dos 2.500 habitantes originais).

\section{CONCLUSÕES}

"Elitização" pode ser considerada uma palavra-chave para definir a experiência carioca na produção da cidade olímpica. Ou, como afirmam os estudiosos do Observatório das Metrópoles (Santos Jr. et al., 2015, p. 13), estamos vivenciando um novo ciclo de mercantilização da cidade, traduzido na incorporação de novas áreas e setores da cidade aos circuitos de acumulação capitalista. As UPPs (Unidades de Polícia Pacificadora), instaladas em diversas favelas, muito mais que a prometida segurança, trouxeram às comunidades a vivência de novos processos de valorização imobiliária e inserção forçada no circuito formal da economia.

Dentre os mais de 70 mil indivíduos removidos no processo de construção da cidade olímpica, a Vila Autódromo representa um porcentual ínfimo, porém de elevado teor simbólico, seja pela repercussão, seja pela intensa mobilização popu- 
lar, seja pelo fato de não haver nenhuma alegação técnica razoável para sua remoção. O principal motor do processo, senão o único, foi o favorecimento de determinados interesses privados na valorização imobiliária do entorno.

Conforme arriscamos supor na introdução deste artigo, essa pode vir a ser a última edição de um ciclo faustoso de Jogos Olímpicos calcados na monumentalidade excessiva e na extravagância de recursos públicos. Pela amplitude das intervenções e pela limitação deste artigo, não podemos ir além destas breves notas. Vale, porém, frisar que, em grande medida, o projeto Rio 2016 se aproxima muito mais do "modelo Pequim 2008" do que de qualquer outro na história do urbanismo olímpico, pela ênfase na monumentalidade, pela abrangência das intervenções e pela natureza autoritária do projeto (Braathen et al., 2014). É, em grande medida, um retrato da atual fase "neodesenvolvimentista" do Brasil. Mas este seria tema para outro artigo.

\section{BIBLIOGRAFIA}

BROUDEHOUX, A.; SÁNCHEZ, F. "The Politics of Mega-event Planning in Rio de Janeiro: Contesting the Olympic City of Exception", in, V. Viehoff; G. Poynter (orgs). Mega-event Cities: Urban Legacies of Global Sports Events. Farnham Surrey (UK), Ashgate, 2015.

BIENENSTEIN, G., SÁNCHEZ, F., MASCARENHAS, G. "The 2016 Olympiad in Rio de Janeiro: Who Can/Could/Will Beat Whom?", in Espaço e Sociedade, ano 7, n. 19, 2012. Disponível em: http://www.uff.br/esportesociedade/index.html.

BRAATHEN, E.; SORBOE, C. M.; MASCARENHAS, G. "BRICS, Mega-sport Events and Rio de Janeiro as a City of Exception", in Tensões Mundiais/World Tensions, v. 10, 2014, pp. 348-62. HARVEY, D. “Do Gerenciamento ao 'Empresariamento': A Transformação da Administração Urbana no Capitalismo Tardio", in Espaço \& Debate, n. 36. São Paulo, Núcleo de Estudos Regionais e Urbanos, 1996, pp. 48-64.

MASCARENHAS, G. "Globalização e Políticas Territoriais: Os Megaeventos Esportivos na Cidade do Rio de Janeiro", in S. Pacheco; M. Machado (orgs.). Globalização, Políticas Públicas e Reestruturação Territorial. Rio de Janeiro, 7 Letras, 2012, pp. 92-108.

"Natureza e Tensões do Urbanismo Olímpico Contemporâneo", in F. Oliveira et al. (orgs.). Geografia Urbana: Ciência e Ação Política. Rio de Janeiro, Consequência, v. 1, 2014, pp. 219-39.

"Barcelona y Río de Janeiro: Diálogo entre Modelos y Realidades del Llamado Urbanismo Olímpico", in Biblio 3w, v. XV. Barcelona, 2010, pp. 1-6.

MASCARENHAS, G.; BIENENSTEIN, G.; SÁNCHEZ, F. O Jogo Continua: Megaeventos Esportivos e Cidades. Rio de Janeiro, Faperj e EdUerj, 2011.

MASSEY, D. World City. London, Potety Press, 2007.

SANTOS JR., O. et al. (org.). Brasil: Impactos da Copa do Mundo 2014 e das Olimpíadas 2016. Rio de Janeiro, 2015.

SMITH, N. The New Urban Frontier: Gentrification and the Revanchist City. New York, Routledge, 1996.

VAINER, C. B. "Pátria, Empresa e Mercadoria. Notas sobre a Estratégia Discursiva do Planejamento Estratégico Urbano", in O. Arantes; C. Vainer; E. Maricato. A Cidade do Pensamento Único. Desmanchando Consensos. Petrópolis, Vozes, 2000. 